\title{
Review
}

\section{Water demand-supply analysis in a large spatial area based on the processes of evapotranspiration and runoff}

\author{
By Toshisuke MARUYAMA ${ }^{* 1, * 2, * 3, \dagger}$ \\ (Communicated by Toshio SAwADA, M.J.A.)
}

\begin{abstract}
To estimate the amount of evapotranspiration in a river basin, the "short period water balance method" was formulated. Then, by introducing the "complementary relationship method," the amount of evapotranspiration was estimated seasonally, and with reasonable accuracy, for both small and large areas. Moreover, to accurately estimate river discharge in the low water season, the "weighted statistical unit hydrograph method" was proposed and a procedure for the calculation of the unit hydrograph was developed. Also, a new model, based on the "equivalent roughness method," was successfully developed for the estimation of flood runoff from newly reclaimed farmlands. Based on the results of this research, a "composite reservoir model" was formulated to analyze the repeated use of irrigation water in large spatial areas. The application of this model to a number of watershed areas provided useful information with regard to the realities of water demand-supply systems in watersheds predominately dedicated to paddy fields, in Japan.
\end{abstract}

Keywords: short period water balance method, complementary relationship method, weighted statistical unit hydrograph method, equivalent roughness method, composite reservoir model

\section{Introduction}

Irrigation and drainage studies involve science and engineering based on watershed hydrological cycles and are indispensable to the mitigation of water shortage/excess conditions toward improved crop growth. Understanding material circulation based on the hydrological cycle is also essential when coping with environmental problems, because water distributes a variety of materials throughout the river basin. Thus, research on the hydrological cycle is fundamental not only to irrigation and drainage studies, but to the solution of environmental problems as well.

The research described herein is pioneering insofar as it entails an analysis of water demand-

\footnotetext{
*1 President of Ishikawa Prefectual University, Ishikawa, Japan.

$* 2 \quad$ Emeritus of Kyoto University.

*3 Recipient of the Japan Academy Prize in 2007

$\dagger$ Correspondence should be addressed: T. Maruyama, Ishikawa Prefectural University, 308 Suematu, Nonoichi-machi, Ishikawa-gun, Ishikawa 921-8836, Japan (e-mail: maruyama@ ishikawa-pu.ac.jp).
}

supply systems in large spatial areas based on the hydrological processes of evapotranspiration and runoff, with a primary focus on paddy fields in Japan.

\section{The study of Evapotranspiration (ET) and its advancement.}

Understanding evapotranspiration (ET) is very important, not only to water resource planning but also to the setting of frameworks for irrigation and drainage. The author and his colleagues have carried out research toward the development of a "short period water balance method" which estimates seasonal ET in a river basin. By introducing the "complimentary relationship theory," we also succeeded in calculating ET using meteorological data such as air temperature, relative humidity, solar radiation, and wind velocity. The model's reliability was then confirmed using field experiments with both the heat balance method and the short period water balance method. In this way, we were able to accurately estimate ET using meteorological data and without making use of seasonal ET coefficients. 


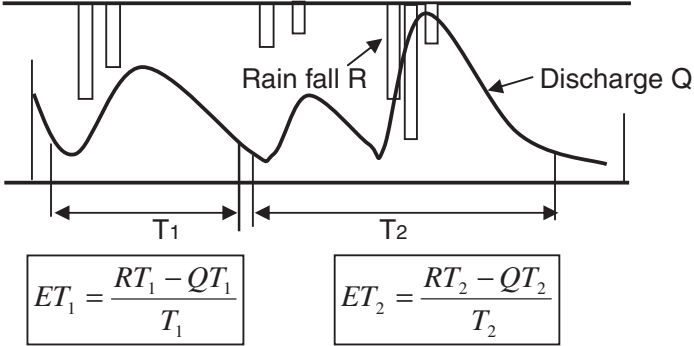

Fig. 1. A schematic presentation of the "short period water balance method".

1.1 The short period water balance method. Pan-evaporation, or small water surface evaporation, has been used as an index of ET in large spatial areas. However, pan-evaporation is not a reliable index with which to estimate $\mathrm{ET}$ for large spatial areas because its ability to objectively represent an area is quite uncertain. $\mathrm{We}^{1)}$ proposed the use of the "short period water balance method," in which ET is estimated by finding the difference between the amount of rainfall and the amount of discharge in a given period, as shown in Fig. 1. This method is based upon the postulation that the amount of storage water in a river basin is the same as long as the rate of river discharge and the recession coefficient of the hydrograph are the same at a low-water level. In keeping with this, ET (ET1) was estimated using the equation shown in Fig. 1.

This method can be applied if groundwater flow at the observation site is negligibly small or can be estimated or measured with sufficient accuracy. For this reason, when we construct a water gage station with a weir, observation sites are usually selected where the bedrock on the bottom of the river is visible. Moreover, in order to obtain a reliable ET estimation, accurate rainfall and discharge data for a long period is also required, but such data can only rarely be obtained in Japan.

One location for which such data is available is Kyoto University's Kamigamo experimental runoff plot, where the author has been engaged in runoff surveys and accurate rainfall and discharge data have been collected for a long period of time. With data for a nine-year period, and making use of the short period water balance method, Takase et al. ${ }^{1)}$ were able to estimate the seasonal ET.

1.2 The estimation of ET in basins using the "complementary relationship method". There are very limited instances in which the "short

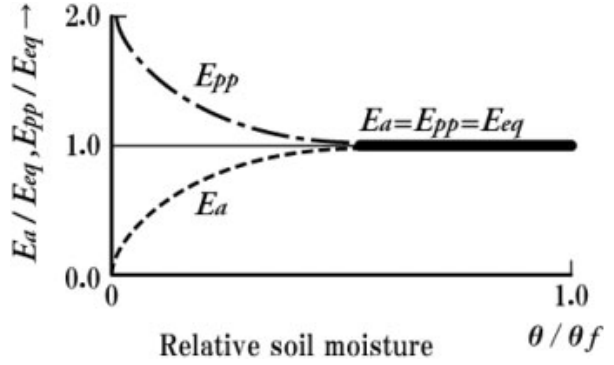

Fig. 2. A schematic depiction of the complementary relationship between actual evapotranspiration (Ea) and estimates of the potential evapotranspiration (Epp) by means of Penman's equation.

period water balance method" is applicable because, as mentioned above, it is difficult to obtain accurate rainfall and discharge data. If ET over a large spatial area could be estimated using ordinary meteorological observation data such as air temperature, relative humidity, radiation, and wind velocity, this would be very useful for water resource and irrigation planning.

However, until recently ET was estimated by multiplying pan-evaporation or Penman's potential evaporation by seasonal evaporation coefficients. If the whole river basin is adequately damp, this method is viable. But if the soil moisture does not meet this condition, as in the dry season or in arid areas, this method is no longer applicable.

The complementary relationship method, which can be applied to areas with less soil moisture, is expressed in equation [1] and in Fig. 2, whereby the sum of potential evaporation (Epp) and actual evaporation (Ea) is equal to twice the equilibrium evaporation (Eeq). Note that this method can be applied in both wet and dry soil conditions.

$$
\mathrm{Epp}+\mathrm{Ea}=2 \mathrm{Eeq}
$$

where Epp is potential ET, Ea is actual ET, and Eeq is equilibrium ET.

Otsuki et $a l .{ }^{2)}$ are the pioneers who introduced this complementary relationship method in Japan. The reliability of this method was confirmed by measurements using the heat balance method at several sites (Fig. 3). ${ }^{3)}$ Further, the effectiveness of this method was confirmed at several runoff experiment stations, making use of the water balance method (Fig. 4). ${ }^{4}$ In this way, basin-wide ET can be estimated without using ET coefficients. In addition, using AMeDAS data, an actual ET map 


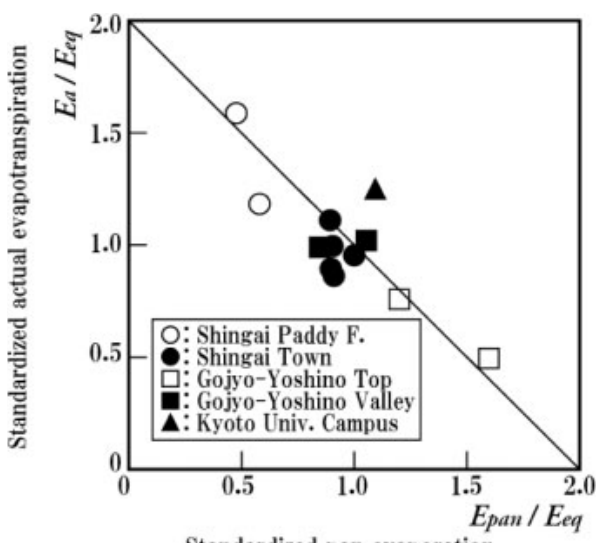

Fig. 3. The relationship between daytime standardized values for actual evaporation (Eah/Eeq) and pan evaporation (Epan/ Eeq).

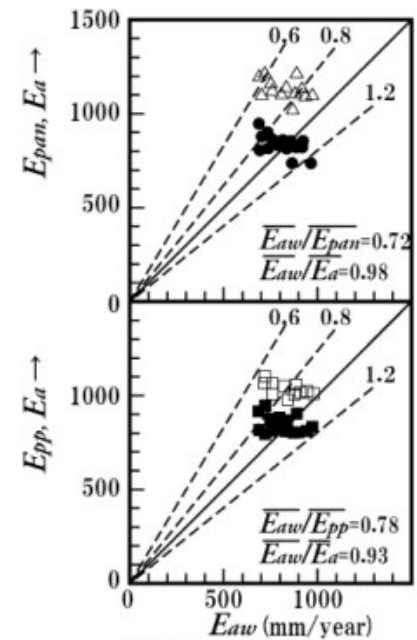

(b) Tatsunokuch

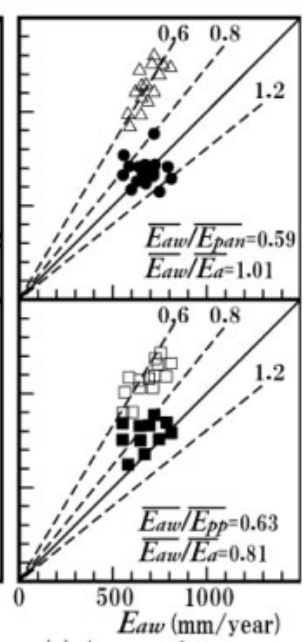

(c) Ananomiya
Fig. 4. A comparison of annual values for evapotranspiration estimated by the complimentary relationships $\left(E_{a c}\right.$ :,$E_{a c}{ }^{\prime \prime}$ : 口), pan evaporation $\left(E_{\text {pan }}: \triangle\right)$, evaporation from free water $\left(E_{0}: \square\right)$ estimated using Penman's equation, and actual evapotranspiration $\left(E_{a w}\right)$ calculated using the water budget method.

was drawn for all of Japan that provided very useful information relevant to water resource planning practices.

Next, with an interest in the allocation of net radiation and heat energy, ET from paddy fields located in urban areas was investigated and it was discovered that ET sometimes exceeded radiation late in the rice growing cycle. ${ }^{5)-7)}$

Also, a net radiation gauge was placed under the plant cover in a paddy field to estimate the

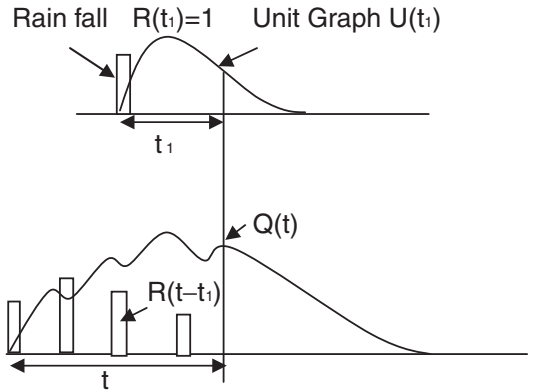

Fig. 5. A schematic presentation of the unit hydrograph and its relation to the discharge.

net radiation that reached the water's surface. Using this data, a model for estimating water temperature in the paddy was formulated. ${ }^{8), 9)}$ After verifying the accuracy of this method, some very useful knowledge was obtained for paddy irrigation water management in areas with relatively cool climates, such as Hokkaido and the Tohoku District in Japan.

\section{Research on runoff and its development.}

Research on runoff investigating the relationship between rainfall and runoff is very important for the planning of water resources, irrigation and drainage, disaster prevention and so on.

2.1 Research on the "weighted statistical unit hydrograph". Maruyama et al. ${ }^{10)}$ proposed that low water discharge could be estimated more accurately by using the weighted least square method to derive a statistical unit hydrograph. The statistical unit hydrograph derived using this new method was named the "weighted statistical unit hydrograph." Here, a "unit hydrograph" is a discharge pattern with time elapsed for a unit of rainfall (Fig. 5). Applying this new method, a river discharge series can be calculated for given rainfall data by superposing the unit hydrograph multiplied by the rainfall for a unit of time as expressed in Eq. [2].

$$
Q(t)=\int_{-\infty}^{\infty} U\left(t_{1}\right) R\left(t-t_{1}\right) d t_{1}
$$

Where $Q(t)$ is the river discharge at time $(t)$, $U\left(t_{1}\right)$ is the unit hydrograph, and $R\left(t-t_{1}\right)$ is the rainfall amount at time $\left(t-t_{1}\right)$.

Because irrigation planning and water resources planning usually require a more accurate prediction of low water discharge than of high 

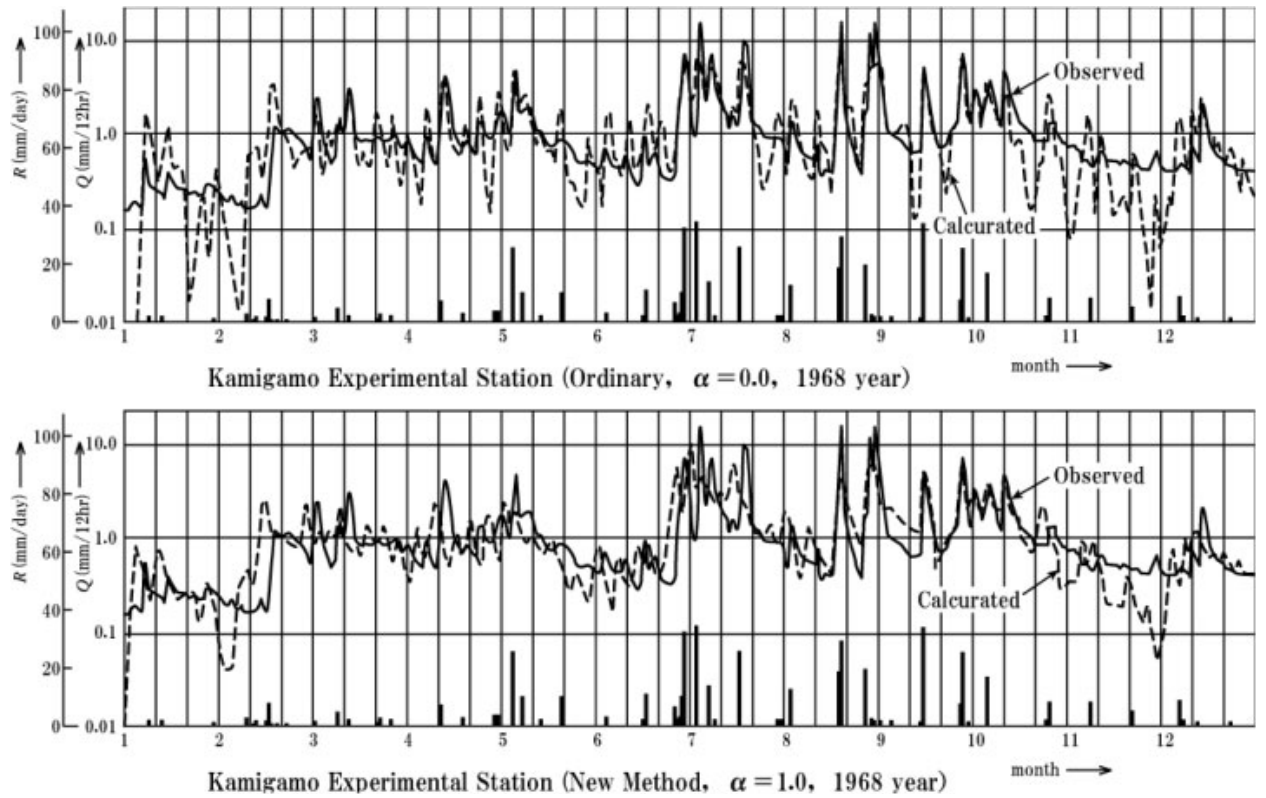

Fig. 6. A comparison of the observed hydrograph and the calculated hydrograph using the conventional (Eq. [3]) and the newly proposed (Eq. [4]).

water discharge, the author proposed the use of the weighted least square method rather than the normal least square method to calculate a statistical unit hydrograph. The conventional criterion for determining a statistical unit hydrograph is expressed in Eq. [3]. However, a new criterion was proposed by the author, as shown in Eq. [4], with the addition of the reciprocal weight of discharge $Q_{l}(t)$. By incorporating Eq. [2] in Eq. [4], we can derive Eq. [5], an m-dimensional first order simultaneous equation. The solution to this equation is a statistical unit hydrograph that can be used to sufficiently predict low water river discharge.

$$
\begin{aligned}
& \varepsilon^{2}(t)=\left\{Q_{l}(t)-Q_{c}(t)\right\}^{2} \\
& \varepsilon^{2}(t)=\frac{1}{Q_{l}^{\alpha}(t)}\left\{Q_{l}(t)-Q_{c}(t)\right\}^{2}
\end{aligned}
$$

where $Q_{l}$ is the linearized observed discharge, $Q_{c}$ is the estimated discharge, $\alpha$ is the weight of the discharge; and $t$ is the time elapsed.

$$
\left[\begin{array}{cccc}
\mathrm{C}(1,1), & \mathrm{C}(1,2) & \cdots & \mathrm{C}(1, \mathrm{~m}) \\
\mathrm{C}(2,1), & \mathrm{C}(2,2) & \cdots & \mathrm{C}(2, \mathrm{~m}) \\
\vdots & \vdots & & \vdots \\
\mathrm{C}(\mathrm{m}, 1), & \mathrm{C}(\mathrm{m}, 2) & \cdots & \mathrm{C}(\mathrm{m}, \mathrm{m})
\end{array}\right]\left[\begin{array}{c}
\mathrm{u}(1) \\
\mathrm{u}(2) \\
\vdots \\
\mathrm{u}(\mathrm{m})
\end{array}\right]
$$

$$
=\left[\begin{array}{c}
E(1) \\
E(2) \\
\vdots \\
E(m)
\end{array}\right]
$$

where $C\left(t_{i}, t_{j}\right), \quad E\left(t_{i}\right)$ are calculated using Eqs. [6] and [7] respectively, Re is the effective rainfall and $2 T$ is the duration of hydrologic data.

$$
\begin{aligned}
C\left(t_{i}, t_{j}\right) & =\lim _{T \rightarrow \infty} \frac{1}{2 T} \int_{-T}^{T} \frac{\operatorname{Re}\left(t-t_{i}\right) \operatorname{Re}\left(t-t_{j}\right)}{Q_{l}^{a}(t)} d t \\
E\left(t_{i}\right) & =\lim _{T \rightarrow \infty} \frac{1}{2 T} \int_{-T}^{T} Q_{l}^{1-a}(t) \operatorname{Re}\left(t-t_{i}\right) d t
\end{aligned}
$$

First, when analysis is carried out on actual observed data, the coherence between rainfall and runoff discharge is investigated. Second, in order to maintain the linearity of rainfall and runoff discharge, high frequency discharge, which is considered to be nonlinear, is eliminated using an appropriate high cut filter. Third, by using Eq. [5] above, the statistical unit hydrograph is calculated. It was confirmed that the discharge estimations using this method were more accurate than when the ordinary method was used, especially in low water periods (Fig. 6). ${ }^{11)}$ 


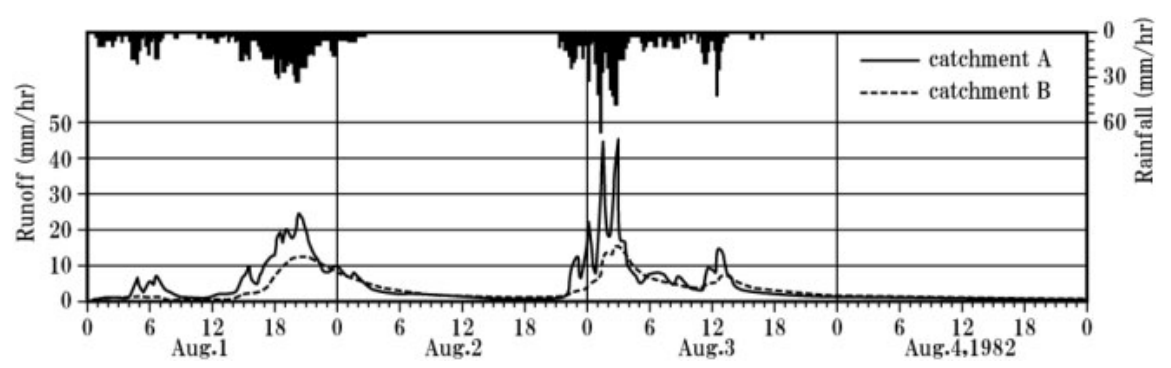

Fig. 7. Storm runoff for the reclaimed land (A) and for the mountainous area (B).

2.2 A runoff analysis for reclaimed agricultural land using the equivalent roughness method. An understanding of runoff from newly reclaimed farmland is very important when designing disaster prevention facilities such as sediment and flood control ponds and channels in reclaimed land. The author and his colleagues set up a pair of small runoff experimentation plots in 1978, one of which was mountainous and the other having reclaimed farmland. Rainfall and runoff were then observed with an automatic recorder over a long period of time. In order to compare the runoff from both plots and identify the direct influence of reclamation, the two experimental plots were set adjacent to one another. Reclaimed farmland was also used as an experimentation plot because hydraulic theories could be easily and clearly applied to analyze rainfall-runoff insofar as the reclaimed farmland was made up of consolidated farm plots with a wellorganized channel system.

As shown in Fig. 7, much more flooding occurred in the reclaimed plot than in the mountainous plot ${ }^{12)}$ This can be explained by the fact that the reclamation works greatly decreased both the soil's permeability and the water holding capacity of the catchment. ${ }^{13)}$ The floods shown in Fig. 7 resulted from two large typhoons, which ravaged the Kinki District at length and caused extensive damage.

Next, using declined and gradient changing lysimeters, equivalent roughness was measured under a rainfall simulator for four types of land cover, namely fallow, bare, grass, and lawn (Fig. 8). ${ }^{14), 15)}$ In order to investigate the physical mechanisms of the runoff phenomena, this roughness was applied independently to the calculation of discharge for the actual reclaimed farmland area. The author et al confirmed that this method could be used to hydraulically explain the runoff phenom-

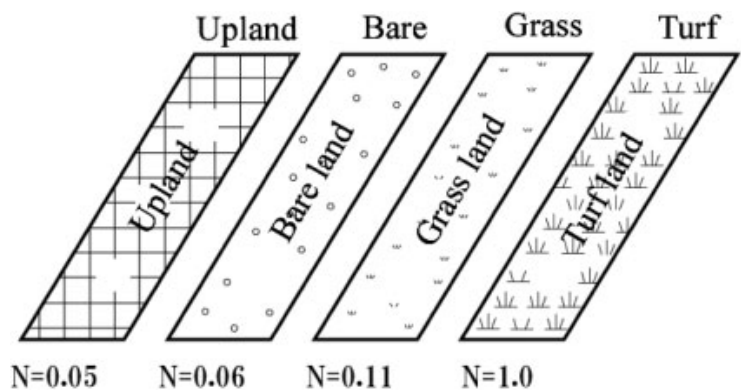

Fig. 8. Land use and equivalent roughness estimated using a lysimeter test.

ena. Moreover, the discharge at a given location in the farmland was estimated accurately through the simulation of rainfall gathering from the farmland into small channels, and then into large channels, using the hydraulic model (Fig. 9). ${ }^{16), 17)}$ Applying this method, the runoff discharge from the reclaimed farmland could be estimated rigorously and with a certain theoretical base, a task that had proved difficult in the past.

Moreover, using a discharge duration analysis for the mountainous area and the reclaimed land for a 12-year period, Takimoto et al. ${ }^{18), 19)}$ found that the low water discharge in the mountainous area was somewhat smaller than it was in the reclaimed farmland (Fig. 10). This result showed that the forested area tended to decrease river discharge in droughty conditions. This phenomenon was thought to result from the fact that in the mountainous area, water in the soil was absorbed by tree roots from a deeper soil horizon even under dry conditions, resulting in a decrease in the river discharge. In contrast, in the reclaimed farmland, a decrease in ET over the catchment caused groundwater flow, which is a substantial component of the river discharge in dry periods, to increase. This would imply that forests in semi-arid regions can not always contrib- 


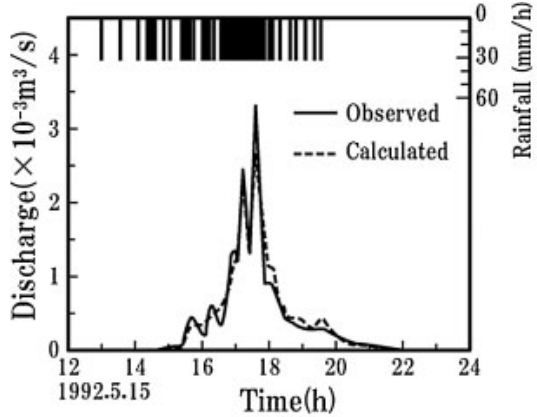

flood 2

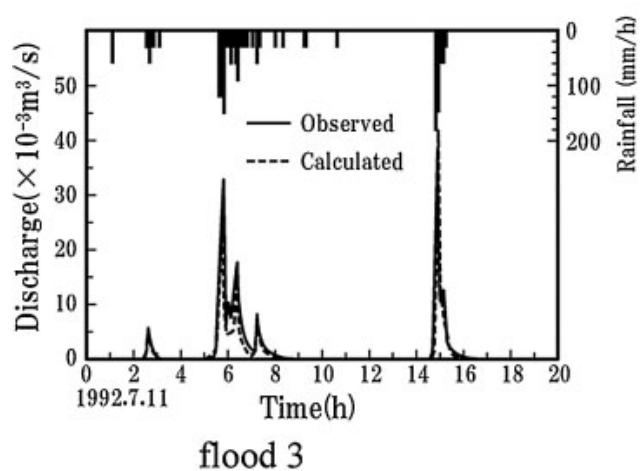

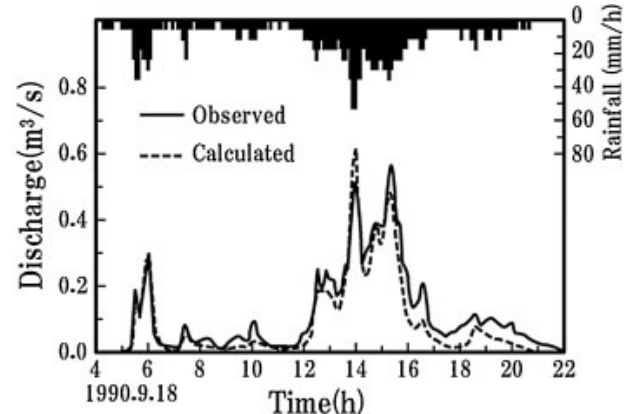

flood 1

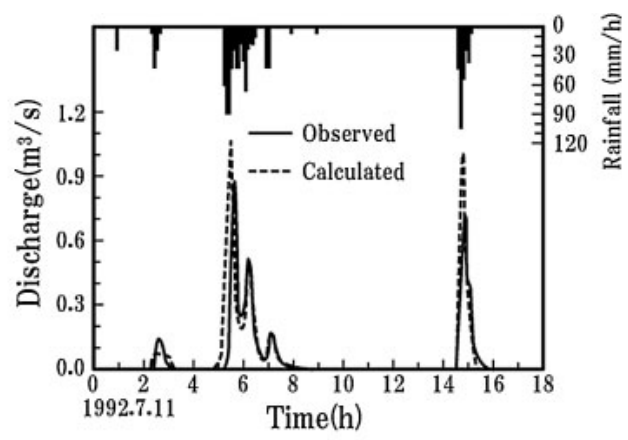

flood 3

Fig. 9. A comparison of observed and calculated hydrographs in reclaimed farmland at the Gojo-Yoshino experimentation plot.

ute to the enhancement of the storage of river water in droughty periods, a finding which is contrary to the generally accepted function of forests.

\section{Water demand-supply analysis in a large spatial area.}

Irrigation water accounts for about $66 \%$ of total water use in Japan. A key feature of irrigation water is that it can be used repeatedly over large spatial areas, making it significantly different from industrial and domestic water use. However, to date, there has been no reasonable method by which to evaluate the actual status of irrigation water.

With this in mind, Maruyama et al. ${ }^{20), 21)}$ devised a new method that makes use of features from both the distributed and lumped models for runoff analysis, and called it the "composite reservoir model" (Fig. 11). Using this model, river discharge can be calculated at any given point on the river. ${ }^{22)}$ This model contributed greatly to the analysis of the repeated use of irrigation water in a large-scale watershed. The non-linear reservoir model is one model that shows promise for the accurate calculation of river discharge from rainfall.
As illustrated in Fig. 11, side holes in the reservoir present runoff to the river from the watershed while bottom holes present percolation to the lower reservoir. The runoff and percolation rates are proportional to the pressure that exceeds the capacity of the holes, and the non-linear relationship between rainfall and runoff can be expressed by these two side holes.

In this model, the whole basin is divided into small units, called "unit basins." In a unit basin, several reservoir models are prepared for each land use, a mountainous area, a paddy field, an upland field, and an urban area (Fig. 12). The reservoir models for the paddy field and upland field are further separated depending on whether the irrigation source is inside or outside the unit basin.

In a model simulation to analyze the demandsupply of irrigation water, the rainfall is added to the upper reservoir and the ET is subtracted from the reservoir. Then, water coming from upstream (both inside and outside the unit basin) is added to the upper reservoir for both the paddy fields and the upland fields if the water level of the reservoirs can not maintain the level required for crop growth. By 

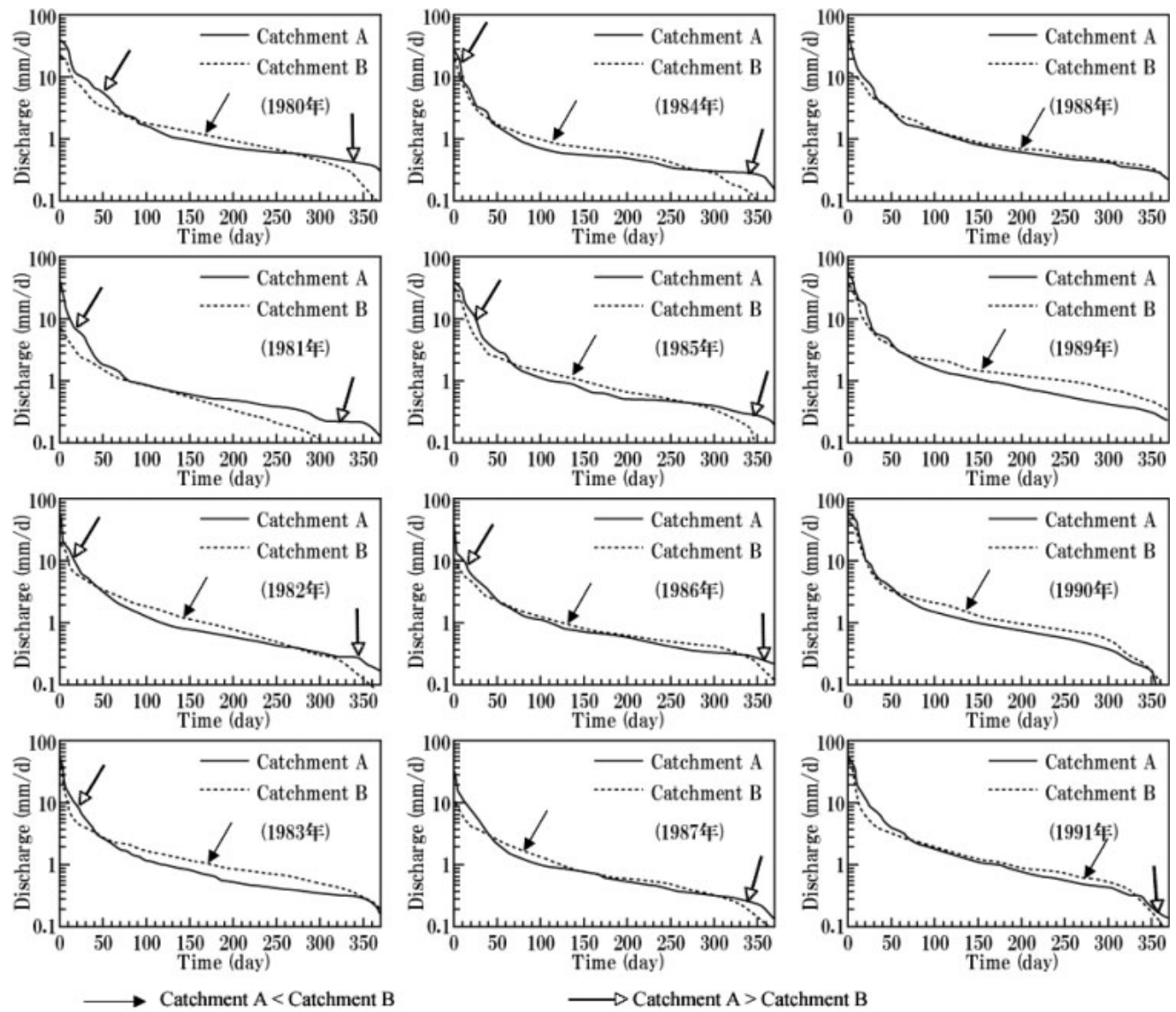

Fig. 10. A comparison of distributions of river discharge for the reclaimed farmland (A) and the mountainous area (B).

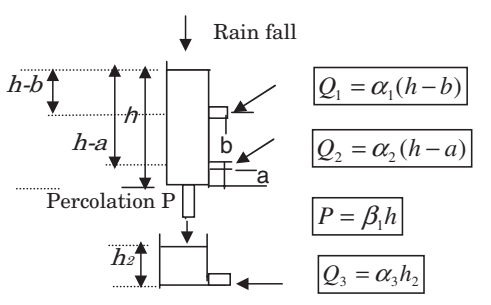

$\alpha_{1}:$ Tank coefficient No.1

$\alpha_{2}:$ Tank coefficient No.2

$\beta_{1}$ :Percolation coefficient

$\alpha_{3}:$ Tank coefficient No.3

$Q_{1}$ : Outflow from No.1 tank of upper hole

$\mathrm{Q}_{2}$ : Outflow from No.1 Tank of lower hole

$\mathrm{Q}_{3}$ : Outflow from No.2 tank

$\mathrm{P}$ : Percolation from No.1 Tank

Q : Total discharge

Fig. 11. The reservoir model concept.

repeating the same procedure for the whole watershed, daily water demand-supply conditions can be analyzed in detail. This model was applied to the Yodo River basin ${ }^{23)}$ in 1964, a droughty year equivalent to a 10-year-recurrence drought year.
The accuracy of this model was verified at several locations along the Yodo River, as shown in Fig. 15.

Using this model, the return flow of irrigation water from an individual unit basin and from the whole basin (Fig. 14) were estimated, and the ratio of the return flow to intake water at the location of the head works was calculated as well (Table 1). Moreover, with this model it was possible to estimate "irrigation sufficiency," or the ratio of intake water to irrigation demand (Fig. 13), useful information when making a water resources development plan. This model was applied to several other major river basins in Japan. ${ }^{24)}$

Some important potential model applications are described below.

3.1 The delineation of unit basins and the purpose of water demand-supply analysis. In the upstream part of the watershed, a unit basin is bounded at the point where the valley becomes narrow and groundwater flow passing the point is 


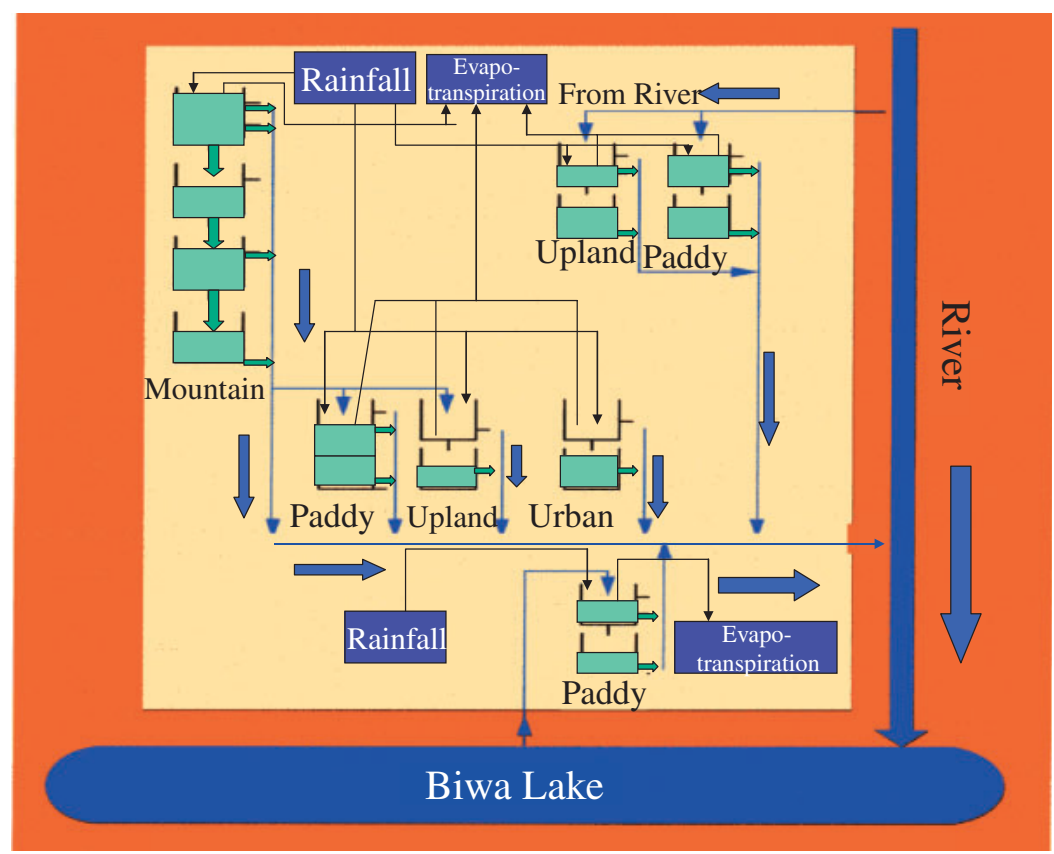

Fig. 12. The structure of the composite reservoir model in a unit basin.

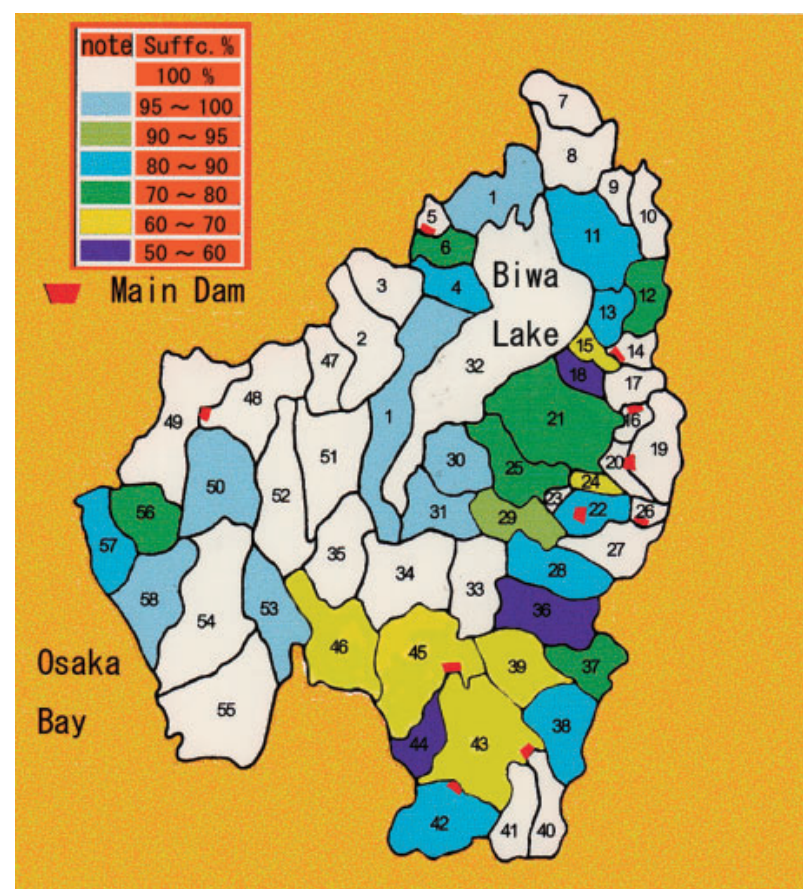

Fig. 13. The shortage of irrigation water in individual unit basins in a droughty year (1964), in the Yodo River basin.

expected to be very limited. In the mid-stream or downstream part of the watershed, the location of head works (irrigation weirs) can act as the

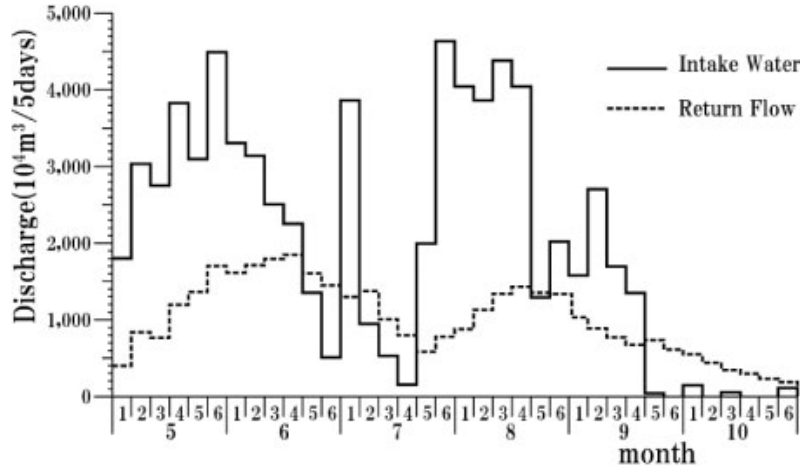

Fig. 14. The amount of intake water at head works and return flow in the whole Yodo River basin in a droughty year (1964).

Table 1. Intake water and Return flow at main river basin. The amount of intake water and return flow in the Yodo River basin (May to October, unit: $10^{4} \mathrm{~m}^{3}, 1964$ )

\begin{tabular}{l|rcc}
\hline & $\begin{array}{c}\text { Intake Water } \\
10^{4} \mathrm{~m}^{3}\end{array}$ & $\begin{array}{c}\text { Return Flow } \\
10^{4} \mathrm{~m}^{3}\end{array}$ & $\begin{array}{c}\text { Ratio of } \\
\text { Return Flow }\end{array}$ \\
\hline Biwa Lake & 40,495 & 16,908 & 0.418 \\
Uji River & 3,068 & 1,423 & 0.464 \\
Kizu River & 12,227 & 5,253 & 0.430 \\
Katura River & 7,828 & 3,825 & 0.489 \\
Down St. Yodo & 5,197 & 1,617 & 0.311 \\
Ina River & 2,100 & 796 & 0.379 \\
\hline Whole Yodo & 70,915 & 29,822 & 0.421 \\
\hline
\end{tabular}



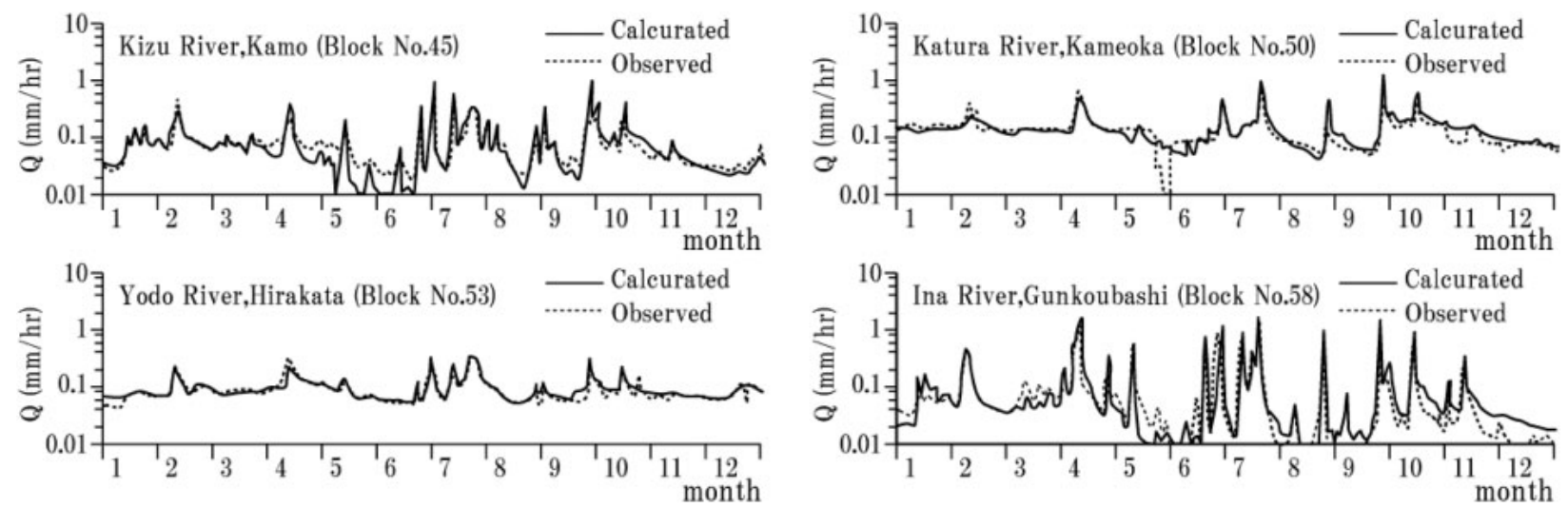

Fig. 15. A comparison of calculated and observed discharge at major observation points along the Yodo River.

boundary points of a unit basin. For water use planning, dam sites or other facilities for water use are considered for the delineation of the unit basin. Other data required by the model includes information regarding areas by land-use class (mountainous area, paddy field, upland field, and urban area), detailed information regarding the river networks and the water use system (irrigation water source and drainage system) and so on.

3.2 Reservoir model constant. When applying the model, the most important issue is how to determine the parameters of the composite reservoir model taking each land-use class into consideration. Hydrological data should be collected as much as possible, and sometimes the construction of new hydrological stations is required for this purpose. Reservoir model constants should also be determined so that the calculated and observed discharges are well matched. Kobayashi et al. ${ }^{25)}$ proposed the use of the non-linear optimization technique, a useful method with which to determine the constants of reservoir models for mountainous areas. To identify the parameters of the reservoir models for paddy fields and upland fields, information on irrigation planning such as irrigation water duties, irrigation intervals, infiltration rates and the water holding capacity of the upland soil is essential. In this way, the model constants are determined in keeping with the physical features of the reservoir model for paddy and upland fields.

3.3 The development of this model. This model can contribute to the analysis of many subjects related to water resources as shown in the example of the Yodo River basin described above. Other subjects this model can be used to address include: (1) changes in river flow due to newly constructed dams and reservoirs, (2) the influence of new irrigation projects on other areas, (3) the appraisal of the function of low water stabilization in paddy fields through an analysis of the relation between intake water and return flow, (4) spatial and seasonal water quality analyses combined with a sub-model for water quality evaluation, and so on.

\section{Acknowledgment}

This article is a brief summary of our research at the Laboratory of Irrigation and Drainage, Kyoto University. The research described here was accomplished with the efforts of many collaborators whose appear in the reference. I wish to express my thanks to them.

\section{References}

1) Takase, K. and Maruyama, T. (1978) Estimation of Catchment ET by Water Balance Method. Trans. JSIDRE 76, 1-6 (in Japanese).

2) Otsuki, K., Mitsuno, T. and Maruyama, T. (1984) Relationship between Pan Evaporation, Potential ET, and Actual ET -Studies on the estimation of actual ET(I)-. Trans. JSIDRE 111, 95103 (in Japanese).

3) Otsuki, K., Mitsuno, T. and Maruyama, T. (1984) Comparison between Water Budget and Complementary Relationship Estimates of Catchments ET (II)-. Trans. JSIDRE 112, 17-23 (in Japanese).

4) Otsuki, K., Mitsuno, T. and Maruyama, T. (1984) Evapotranspiration in Japan Estimated from Meteorological Data -Studies on the estimation of actual evapotranspiration (III)-. Trans. JSIDRE 112, 25-32 (in Japanese).

5) Otsuki, K., Jahanbakhsh-Asl, S. and Maruyama, T. (1987) Energy Distribution of the Rice Plant Canopy -Fundamental Studies on Evapotranspi- 
ration in Paddy Fields (I)-. Trans. JSIDRE 130, $17-23$.

6) Jahanbakhsh-Asl, S., Otsuki, K. and Maruyama, T. (1987) Analysis of Heat and Water Movement through a Rice Plant Canopy by Two Layer Model -Fundamental Studies on Evapotranspiration in Paddy Fields (II)-. Trans. JSIDRE 30, $25-31$.

7) Jahanbakhsh-Asl, S., Mitsuno, T., Otsuki, K. and Maruyama, T. (1987) Mechanism of Latent and Sensible Heat Flux Partitioning in The Rice Plant Canopy -Fundamental Studies on Evapotranspiration in Paddy Fields (III)-. Trans. JSIDRE 132, 11-19.

8) Ohara, Y., Otsuki, K., Takizawa, I. and Maruyama, T. (1985) Energy Budget of Rice Planted Paddy Field, and Estimation of Its Water temperature -Studies on water temperature and water management for paddy fields(II)-. Trans. JSIDRE 119, 21-27 (in Japanese).

9) Ohara, Y., Otsuki, K., Takizawa, I. and Maruyama, T. (1986) Variation of Water Temperature with Rice Growth, and it's Estimation -Studies on water temperature and water management for paddy fields(II)-. Trans. JSIDRE 123, 33-40 (in Japanese).

10) Maruyama, T. and Fujioka, Y. (1973) Fundamental Studies for the Determination of Unit Hydrograph by Weighted Least Square Minimum Method -The analysis of low stream flow by statistical unit hydrograph (I)-. Trans. JSIDRE 43, 33-38 (in Japanese).

11) Maruyama, T. and Fujioka, Y. (1973) Application of Unit Hydrograph Method by Weighted Least Square Minimum Method -The analysis of low stream flow by statistical unit hydrograph (II)-. Trans. JSIDRE 43, 39-45 (in Japanese).

12) Kobayashi, S., Tanakamaru, H. and Maruyama, T. (1984) Runoff Properties in Reclaimed Agricultural Land, -Change in runoff properties due to reclamation (I). Trans. JSIDRE 113, 1-7 (in Japanese).

13) Tanakamaru, H., Kobayashi, S. and Maruyama, T. (1984) -Runoff Analysis in Agricultural Land Considering Spatial Variability of permeability, -Change in runoff properties due to reclamation, (II)-. Trans. JSIDRE 113, 8-16 (in Japanese).

14) Horino, H., Chin, E., Hayase, Y. and Maruyama, T. (1992) Experimental Studies on Roughness Coefficients for Overland Flow under a Controlled Rainfall -Fundamental studies on drainage planning for reclaimed land (I)-. Trans. JSIDRE 158 , 87-94 (in Japanese).

15) Chin, E., Horino, H., Hayase, Y. and Maruyama, T. (1992) Experimental Studies on Roughness Coefficient for Uniform Flow -Fundamental studies on drainage planning for reclaimed land (II)Trans. JSIDRE 160, 43-49 (in Japanese).
16) Chin, E., Watanabe, T., Horino, H. and Maruyama, T. (1993) Estimation Runoff Hydrograph Using Physical Models in Field Lot and Catchments Level -Fundamental studies on drainage planning for reclaimed land (III)-. Trans. JSIDRE 164, 135-139 (in Japanese).

17) Chin, E., Watanabe, T., Horino, H. and Maruyama, T. (1993) Evaluating Rainfall Loss and Estimating Runoff Hydrograph and Peak Discharge -Fundamental studies on drainage planning for reclaimed land (IV)-. Trans. JSIDRE 164, 141-146 (in Japanese).

18) Takimoto, H., Tanaka, T., Horino, H., Watanabe, T. and Maruyama, T. (1994) Does Forest Conserve Runoff Discharge during Drought? -A case study of Gojo-Yoshino area-. Trans. JSIDRE 170, 75-81 (in Japanese).

19) Takimoto, H., Horino, H., Watanabe, T. and Maruyama, T. (1994) Comparison of ET Properties between a Reclaimed Farmland and Natural Forest -Catchments evapotranspiration estimates by the short time water budget methodJ. Japan Soc. Hydrology \& Water Resources, Vol. 7, No. 6, pp. 529-535 (in Japanese).

20) Maruyama, T., Tomita, M. and Kobayashi, S. (1975) An Analysis of Repeated Use of Water for Agriculture in the Yodo River Basin Using Complex Reservoir Model. IASH Symposium, Tokyo, pp. 725-734.

21) Maruyama, T., Tomita, M. and Kobayashi, S. (1979) Water Balance Analysis in Large Spatial Areas using the Composite Reservoir Model-1. The Features and Structure of the Composite Reservoir Model. Jour. JSDRE 47 (2), 97-102 (in Japanese).

22) Tomita, M., Kobayashi, S. and Maruyama, T. (1979) Water Balance Analysis in Large Spatial Areas using the Composite Reservoir Model-2. The Operation of the Composite Reservoir Model. Jour. JSDRE 47 (3), 189-194 (in Japanese).

23) Kobayashi, S., Fujimori, S., Tomita, M. and Maruyama, T. (1979) Water Balance Analysis in Large Spatial Areas using the Composite Reservoir Model-3. Its Application to the Yodo River Basin. Jour. JSDRE 47 (4), 255-260 (in Japanese).

24) Kobayashi, S. and Maruyama, T. (1979) Water Balance Analysis in Large Spatial Areas using the Composite Reservoir Model-4 Its Application to the Kiso River Basin-. Jour. JSDRE 47 (7), 487491 (in Japanese).

25) Kobayashi, S. and Maruyama, T. (1976) Search for Coefficient of Reservoir Model with the Powell's Conjugate Direction Method. Trans. JSIDRE 65, 42-47 (in Japanese).

(Received July 30, 2007; accepted Aug. 16, 2007) 


\section{Profile}

Toshisuke Maruyama was born in 1933. He graduated from Kyoto University in 1956 and began his research career on underdrainage of agricultural land at National Institute for Agricultural Sciences, Ministry of Agriculture and Forestry. He returned to Kyoto University in 1966 as Assistant Professor in the Faculty of Agriculture and was promoted to Associate Professor in 1967 and then Professor in 1973. Professor Maruyama later became Dean of the Faculty of Agriculture at Kyoto University in 1994. After retiring in 1997, he joined the Faculty of Bioresource Sciences at Nihon University and in 1999 assumed the presidency of Ishikawa Agricultural College. When Ishikawa Agricultural College became Ishikawa Prefectural University in 2005, he continued to serve as President of this university to 2006. Professor Maruyama

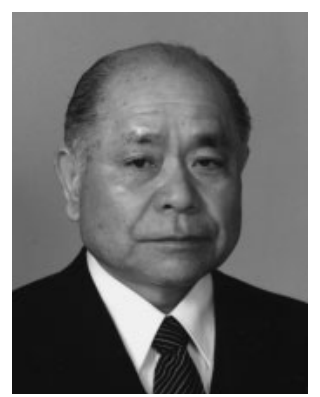
was awarded the Irrigation, Drainage and Reclamation Engineering Award in 1992, Japan Agricultural Sciences Award in 1999, Yomiuri Agricultural Sciences Award in 1999, Paddy and Water Environment Engineering Award in 2003 and Japan Academy Prize in 2007. 